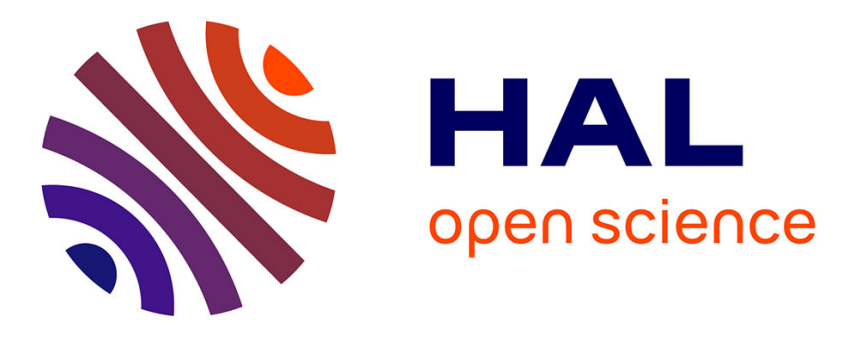

\title{
Organocatalytic Cleavage of Fatty 1,2-Diketones to Esters
}

Nam Duc Vu, Romain Chavallard, Thomas de Dios Miguel, Nicolas Duguet, Marc Lemaire

\section{- To cite this version:}

Nam Duc Vu, Romain Chavallard, Thomas de Dios Miguel, Nicolas Duguet, Marc Lemaire. Organocatalytic Cleavage of Fatty 1,2-Diketones to Esters. ACS Sustainable Chemistry \& Engineering, 2019, 7 (16), pp.13865-13872. 10.1021/acssuschemeng.9b02026 . hal-03245770

\section{HAL Id: hal-03245770 \\ https://hal.science/hal-03245770}

Submitted on 2 Jun 2021

HAL is a multi-disciplinary open access archive for the deposit and dissemination of scientific research documents, whether they are published or not. The documents may come from teaching and research institutions in France or abroad, or from public or private research centers.
L'archive ouverte pluridisciplinaire HAL, est destinée au dépôt et à la diffusion de documents scientifiques de niveau recherche, publiés ou non, émanant des établissements d'enseignement et de recherche français ou étrangers, des laboratoires publics ou privés. 


\section{Organocatalytic Cleavage of Fatty 1,2-Diketones to}

\section{Esters}

Nam Duc Vu, ${ }^{a}$ Romain Chavallard, ${ }^{a}$ Thomas De Dios Miguel, ${ }^{a}$ Nicolas Duguet, ${ }^{*} a$ Marc Lemaire $^{a}$

${ }^{a}$ Univ Lyon, Université Claude Bernard Lyon 1, CNRS, INSA-Lyon, CPE-Lyon, Institut de Chimie et Biochimie Moléculaires et Supramoléculaires, ICBMS, UMR 5246, Equipe CAtalyse, SYnthèse et ENvironnement (CASYEN), Bâtiment Lederer, 1 rue Victor Grignard, F-69100 Villeurbanne, France.

e-mail: nicolas.duguet@univ-lyon1.fr

KEYWORDS. Vegetable oils, 1,2-Diketones, Organocatalysis, Oxidative cleavage, Esters.

ABSTRACT. The cleavage of a fatty 1,2-diketone derived from methyl oleate into the corresponding esters, i.e., methyl nonanoate and dimethyl azelate was studied by organocatalysis using oxygen as a clean oxidant. Only carbene generated from thiazolium salts and $\mathrm{K}_{2} \mathrm{CO}_{3}$ could efficiently catalyze this transformation. It was found that, under the optimized conditions, the oxidative cleavage leads to the formation of a 1:1 mixture of esters and potassium carboxylates. An acidic treatment of the mixture, followed by esterification with methanol, led to the desired 
esters with 75 and $77 \%$ yield. This protocol was extended to a range of symmetrical and unsymmetrical fatty 1,2-diketones and the corresponding esters were isolated with $61-84 \%$ yield.

\section{INTRODUCTION}

The development of new methodologies for the formation of carbon-carbon bonds has thoroughly occupied chemists during most of the last century, notably for increasing molecular complexity. In contrast, with the development of green and sustainable chemistry, the use of renewable resources is now often requiring the development of cleavage methods to produce chemicals with higher added-value. ${ }^{1}$ Among the primary components of biomass, vegetable oils and fatty acid derivatives have attracted a lot of attention due to their wide availability, low cost and low toxicity. ${ }^{2-6}$ Unsaturated fatty compounds are particularly interesting since they can be cleaved to shorter fragments that could be used in the preparation of bio-based surfactants ${ }^{7-10}$ and polymers. ${ }^{11,12}$ Besides the specific thermal cracking of ricinoleic derivatives ${ }^{13-15}$ and the crossmetathesis with ethylene derivatives, ${ }^{16-19}$ most of the reported cleavage methods rely on the use of oxidants (oxidative cleavage). Therefore, they involve the formation of oxidized intermediates that are produced in-situ or prepared on purposes. The oxidative cleavage of ozonides, epoxides and 1,2-diols has been intensively studied, ${ }^{20-26}$ notably for the preparation of aldehydes, acids and esters. However, only very little attention has been devoted to fatty $\alpha$-hydroxyketones ${ }^{27-34}$ and 1,2-diketones, ${ }^{35-37}$ even though these compounds are usually proposed as reaction intermediates.

In this context, we have recently reported the preparation of fatty $\alpha$-hydroxyketones by either selective oxidation ${ }^{38}$ or dehydrogenation of the corresponding fatty 1,2 -diols. ${ }^{38,39}$ These $\alpha$ hydroxyketones can be cleaved to the corresponding acids using $\mathrm{H}_{2} \mathrm{O}_{2} \cdot{ }^{39}$ Alternatively, they can 
be cleaved to aldehydes through a retro-benzoin process catalyzed by thiazolium salts under reactive distillation conditions. ${ }^{40-42}$

However, to the best of our knowledge, no example has been reported for the cleavage of fatty 1,2-diketones to the corresponding acids or esters. Actually, there are very few examples for the cleavage of 1,2-diketones ( $\alpha$-diketones). For instance, aromatic or aliphatic 1,2-diketones can be cleaved using bleach (10 equiv) to give the corresponding acids with good yields. ${ }^{43}$ Moreover, it was also demonstrated that cyclic 1,2-diketones can also be cleaved to the corresponding esters using $\mathrm{KHSO}_{5}$ (Oxone, 4 equiv) in methanol. ${ }^{44}$ These two methods are relatively efficient but require the use of oxidants in large excess. Alternatively, catalytic methods were also developed for the cleavage of 1,2-diketones. In 1958, Kwart and Baevsky reported a kinetic study showing that the cyanide ion could catalyze the cleavage of aromatic diketones (benzils) into the corresponding aldehyde and ester. ${ }^{45}$ This reaction was recently re-investigated by Sessler et al. in order to develop a selective cyanide indicator. ${ }^{46}$ The authors showed that symmetrical benzil derivatives can be cleaved using tetrabutyl ammonium cyanide to give the corresponding aldehyde and ester in high yields. More recently, during the course of mechanism studies of the NHC-catalyzed oxidative esterification of aldehydes, Connon et al. showed that benzil was cleaved into aldehyde and ester in the presence of a triazolium precatalyst. ${ }^{47}$ However, when the reaction was conducted in a mixture of $\mathrm{THF} / \mathrm{MeOH}$ under anaerobic conditions (argon), methyl benzoate was only obtained with $50 \%$ yield. The same authors later reported the cleavage of cyclic aromatic 1,2-diketones to the corresponding diacids using similar conditions but under aerobic conditions (air) using a THF/ $/ \mathrm{H}_{2} \mathrm{O}$ mixture. ${ }^{48}$ The diacids were not isolated but further esterified using methyl iodide to give the diesters with good yields. However, when 1,2cyclohexanedione was used, dimethyl adipate was only obtained with $18 \%$ yield, thus showing 
the limitation of this method when aliphatic substrates are used as starting materials. In this context, we report here an efficient organocatalytic method for the cleavage of fatty 1,2diketones to the corresponding esters using oxygen as a clean oxidant (Scheme 1).

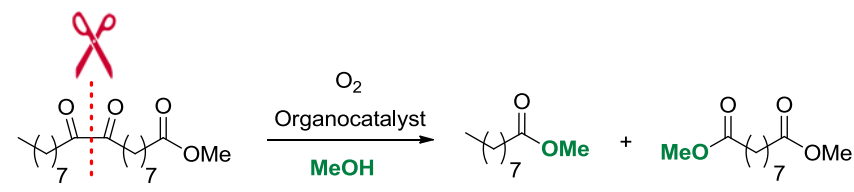

Scheme 1. Organocatalytic cleavage of fatty 1,2-diketones to esters.

\section{RESULTS AND DISCUSSION}

\section{Preparation of fatty 1,2-diketones}

Three main methods have been described in the literature for the preparation of fatty 1,2diketones. First, unsaturated fatty acids can be directly oxidized to 1,2-diketones using $\mathrm{KMnO}_{4}$ under extremely diluted conditions $\left(2\right.$ g.L $\left.L^{-1}\right) .{ }^{35}$ Second, they can be prepared from the corresponding epoxides using DMSO as an oxidant in the presence of $\mathrm{Bi}(\mathrm{OTf})_{3}{ }^{36}$ Third, fatty 1,2-diols can be also oxidized to 1,2-diketones using NBS as an oxidant in the presence of pyridine in $\mathrm{CCl}_{4} \cdot{ }^{37}$ Although these methods give access to the desired products, they rely on toxic oxidants, thus leading to large quantities of waste. So, no clean (catalytic) oxidation method for the preparation of fatty 1,2-diketones has been reported to date. Considering that we have recently developed two green methods ${ }^{38,39}$ for the preparation of fatty $\alpha$-hydroxyketones, we envisioned to use these key intermediates for the preparation of fatty 1,2-diketones. 
The oxidation of the fatty $\alpha$-hydroxyketone derived from methyl oleate to the corresponding 1,2diketone was first investigated under metal-free conditions using DBU under air. Indeed, these conditions were reported to be efficient for the oxidation of benzoins to benzils, ${ }^{49}$ and more recently, for the conversion of bio-based furoins to the corresponding $\alpha$-diketones ${ }^{50}$ However, in our case, only $5 \%$ of the desired fatty diketone was obtained, probably due to the fact that aliphatic $\alpha$-hydroxyketones are more difficult to oxidize than aromatic ones (i.e., benzoins and furoins). Consequently, we have then focused our attention on a metal-based approach for the preparation of fatty 1,2-diketones.

Inspired from the work of Kirihara, ${ }^{51}$ the $\alpha$-hydroxyketones were oxidized using oxygen as a clean oxidant using $\mathrm{VOCl}_{3}$ as a catalyst $(1 \mathrm{~mol} \%)$. The reaction was carried out in $\mathrm{CH}_{3} \mathrm{CN}$ at room temperature for 18 hours (Figure 1).

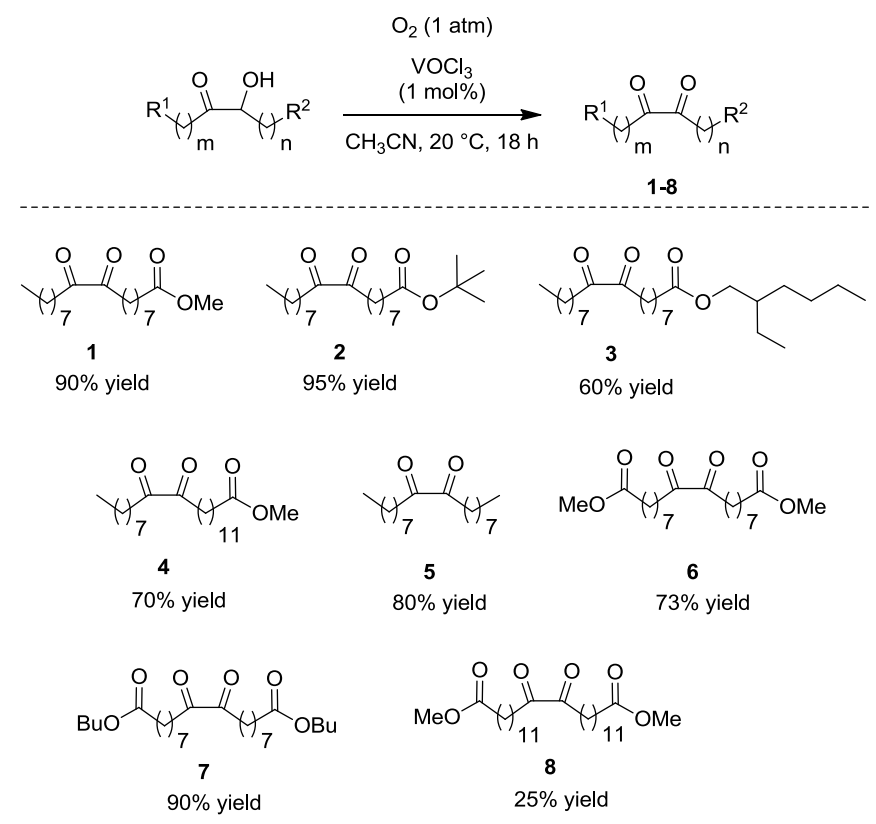

Figure 1. Preparation of fatty 1,2-diketones from $\alpha$-hydroxyketones. 
The reaction proceeded smoothly with unsymmetrical $\alpha$-hydroxyketones (1:1 mixture of regioisomers) derived from methyl oleate, tert-butyl oleate, 2-ethylhexyl oleate and methyl erucate and the corresponding 1,2-diketones 1-4 were obtained with $60-95 \%$ isolated yield. Similarly, symmetrical fatty $\alpha$-hydroxyketone derivatives were also converted to the corresponding 1,2-diketones 5-7 with high yields (73-90\%). However, fatty diketone 8 was only obtained with $25 \%$ yield due to the low solubility of the starting material under the conditions used.

\section{Cleavage of fatty 1,2-diketones to esters}

With a range of fatty 1,2-diketones in hands, their organocatalytic cleavage to esters was first investigated using diketone $\mathbf{1}$ as a model substrate. The reaction was first carried out under air (1 atm) in the presence of thiazolium precatalyst $9(20 \mathrm{~mol} \%)$ and $\mathrm{K}_{2} \mathrm{CO}_{3}(20 \mathrm{~mol} \%)$ in $\mathrm{MeOH}$ at $65^{\circ} \mathrm{C}$ (Table 1). ${ }^{52}$

Table 1. Influence of atmospheric conditions for cleavage of diketone. ${ }^{a}$

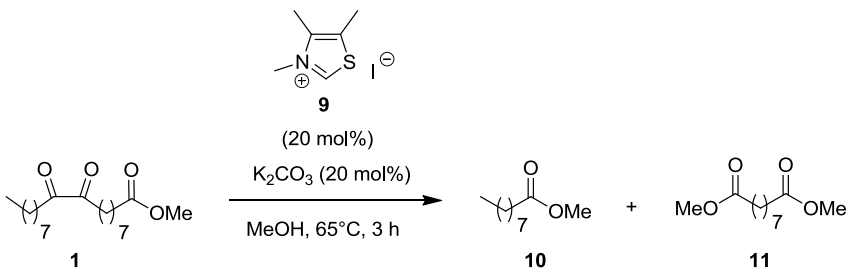

\begin{tabular}{lllll}
\hline Entry & Atmosphere & Conv. $^{b}(\%)$ & Yield $^{b}(\%)$ & Yield $^{b}(\%)$ \\
\hline 1 & Air & 99 & 33 & 25 \\
2 & $\mathrm{O}_{2}$ & 99 & 35 & 33 \\
3 & Argon & 15 & - & -
\end{tabular}


${ }^{a}$ Reaction conditions: $25-\mathrm{mL}$ Schlenk flask, diketone $1(0.5 \mathrm{mmol})$, thiazolium salt 9 (20 mol\%), $\mathrm{K}_{2} \mathrm{CO}_{3}(20$ mol\%), $\mathrm{MeOH}(0.5 \mathrm{M}), 65^{\circ} \mathrm{C}, 3 \mathrm{~h} .{ }^{b}$ Conversion and yield of products were determined by GC using $n$ hexanedecane as an internal standard. ${ }^{c} 100 \mathrm{~mol} \%$ of $\mathrm{K}_{2} \mathrm{CO}_{3}$ was used.

Under these conditions, methyl pelargonate $\mathbf{1 0}$ and dimethyl azelate $\mathbf{1 1}$ were obtained with 33 and $25 \%$ yield, respectively (Table 1 , entry 1 ). When the reaction was conducted under oxygen, the yields slightly increased to 35 and $33 \%$ (Table 1, entry 2 ). These moderate yields could be explained by the formation of two heavier products $\mathbf{1 2}$ and $\mathbf{1 3}$ that could be observed in the GC chromatogram (Figure 2).

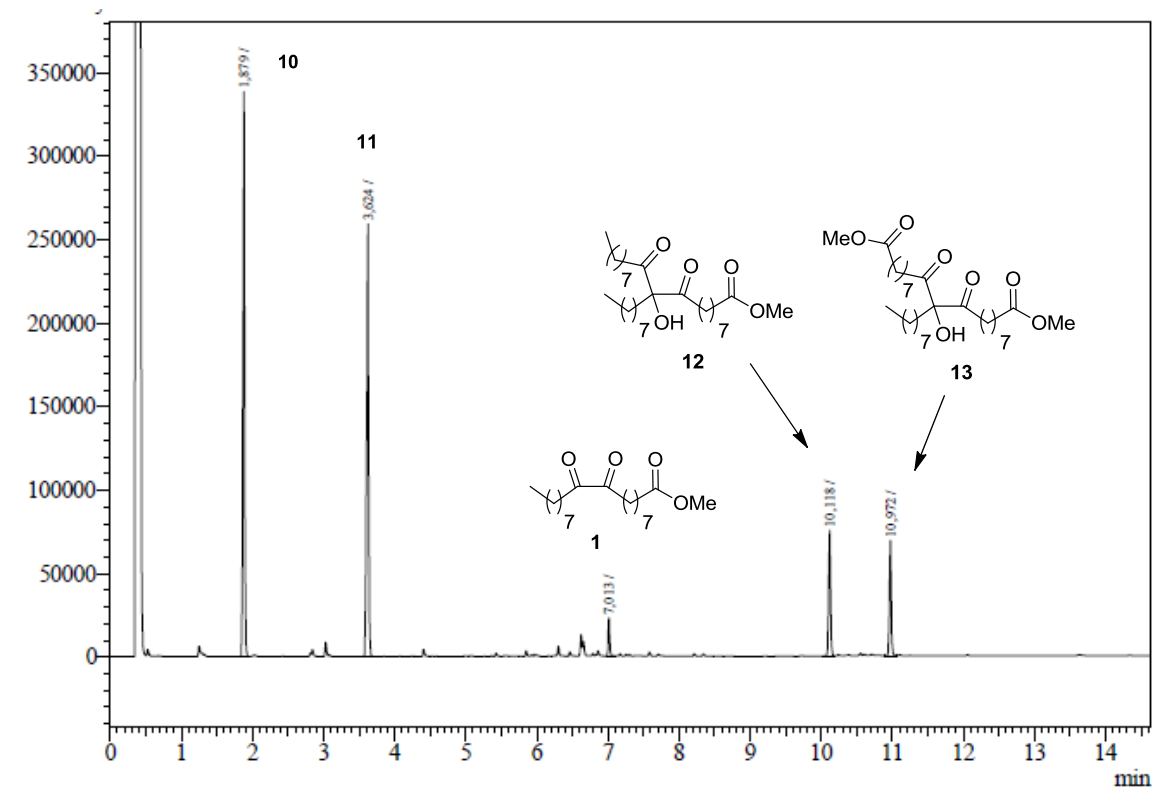

Figure 2. GC chromatogram of the oxidative cleavage of 1,2-diketone 1 (from Table 1, entry 1).

In fact, the formation of these by-products could be explained from a mechanism point of view (Figure 3). 


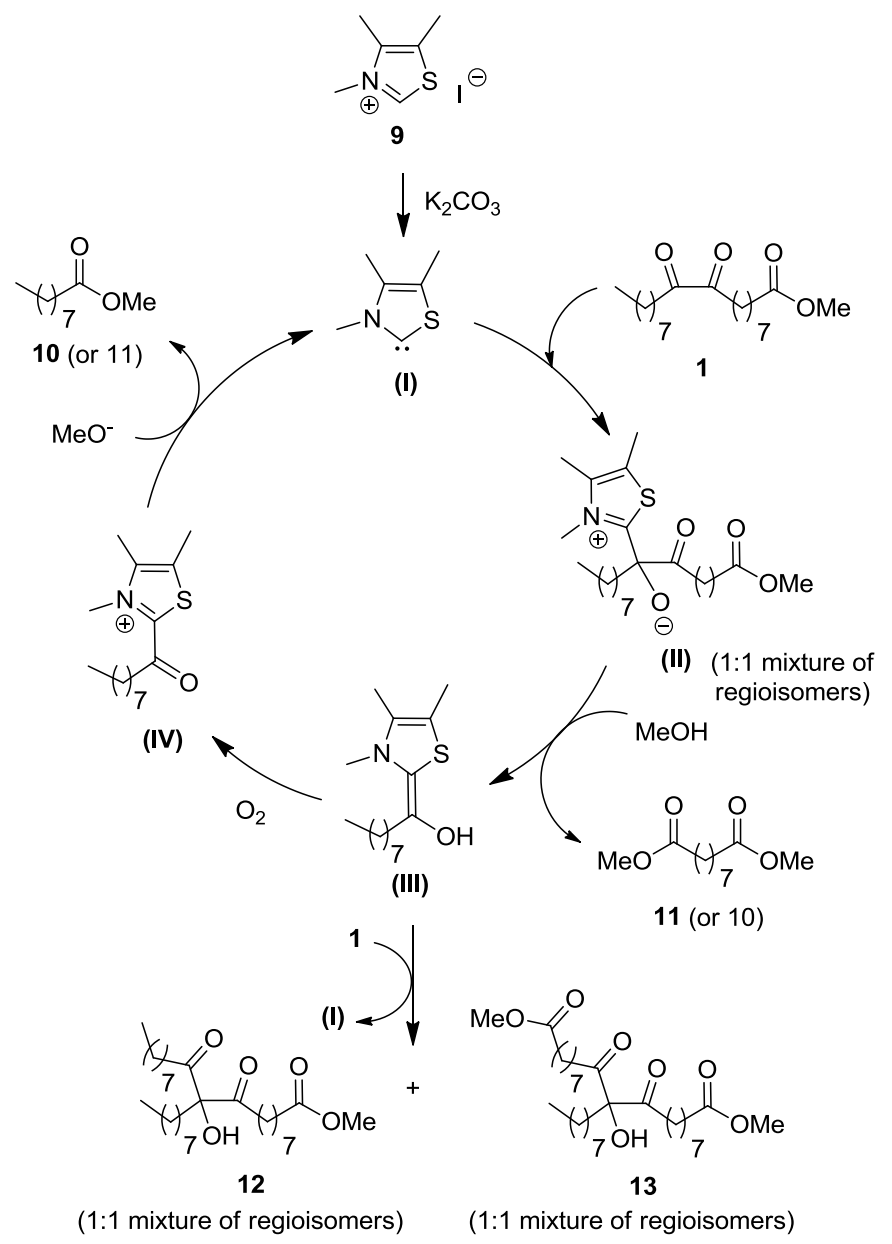

Figure 3. Proposed mechanism for the cleavage of 1,2-diketones to esters and formation of the byproduct (only one regioisomer is represented for clarity).

First, thiazolium 9 is deprotonated in the presence of $\mathrm{K}_{2} \mathrm{CO}_{3}$ to generate the active thiazolylidene species (I). The free carbene could undergo nucleophilic addition onto diketone $\mathbf{1}$ to form intermediate (II) as 1:1: mixture of regioisomers. This species could be cleaved in the presence of methanol to give a first ester and Breslow intermediate (III). Then, there are two possible pathways from this key intermediate. On the one hand, the Breslow intermediate could be oxidized in the presence of oxygen to form the acyl thiazolium species (IV), following by nucleophilic addition of methoxide to liberate a second ester and the free carbene. This first pathway is thus involved in the formation of the desired esters $\mathbf{1 0}$ and 11. On the other hand, the 
Breslow intermediate (III) could add onto diketone $\mathbf{1}$ via acyl anion transfer to form the coupling products 12 and 13 that were observed by GC. It should be noted that each compound is a mixture of two regioisomers that overlap on the GC chromatogram.

The formation of such compounds was previously demonstrated by Massi et al. who showed that $\alpha$-diketones could be used as acyl anion equivalents to give $\alpha$-hydroxy 1,3 -diketones in the presence of a thiamine-based catalyst. ${ }^{53}$ However, the formation of these $\alpha$-hydroxy $1,3-$ diketones is only predominant when the reaction is conducted without any oxidant. This is in accordance with our results obtained when the reaction was carried out under argon atmosphere (Table 1, entry 3). Indeed, under these conditions, the conversion reached $15 \%$ and only byproducts 12 and 13 were observed (esters 10 and 11 were not detected). In order to improve the results, the formation of such compounds should be avoided. According to Connon et al., $\alpha$ hydroxy 1,3-diketones could be cleaved to ester and $\alpha$-hydroxyketone in the presence of $\mathrm{MeOH}$ and base, through the formation of a hemi-ketal. ${ }^{47}$ In our case, compounds $\mathbf{1 2}$ and $\mathbf{1 3}$ could produce esters 10 and 11 and the corresponding $\alpha$-hydroxyketone $\mathbf{1 4}$ could be further oxidized to regenerate 1,2-diketone 1 (Scheme 2).

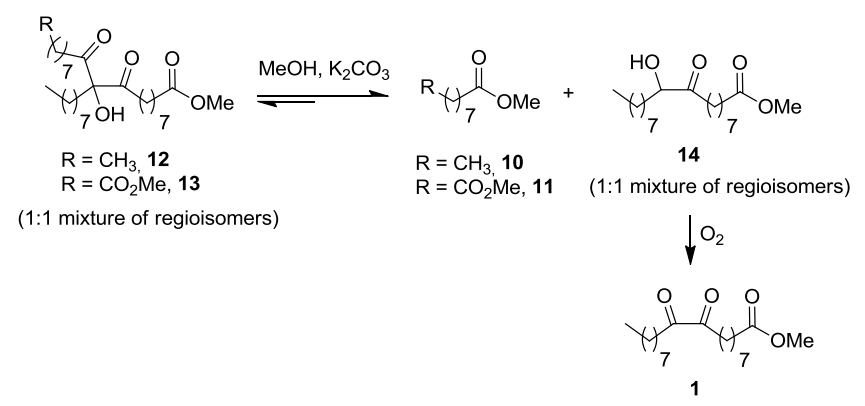

Scheme 2. Cleavage of $\alpha$-hydroxy 1,3-diketones to ester and $\alpha$-hydroxyketone. 
So, in order to promote this reverse reaction, the reaction was carried out under oxygen but with an excess of $\mathrm{K}_{2} \mathrm{CO}_{3}(100 \mathrm{~mol} \%$ ) (Table 1, entry 4). Satisfyingly, the yield of esters $\mathbf{1 0}$ and $\mathbf{1 1}$ increased to 38 and 39\%, respectively, and no trace of byproducts $\mathbf{1 2}$ and $\mathbf{1 3}$ was observed by GC. Consequently, these conditions were selected for futher optimization.

A range of commercially available azolium salts was next screened as precatalysts for the oxidative cleavage of 1,2-diketone 1 under typical conditions (20 mol\% of azolium salt, 100 mol\% of $\mathrm{K}_{2} \mathrm{CO}_{3}$ ) (Table 2). 
Table 2. Screening of precatalysts for the oxidative cleavage of diketone. ${ }^{a}$

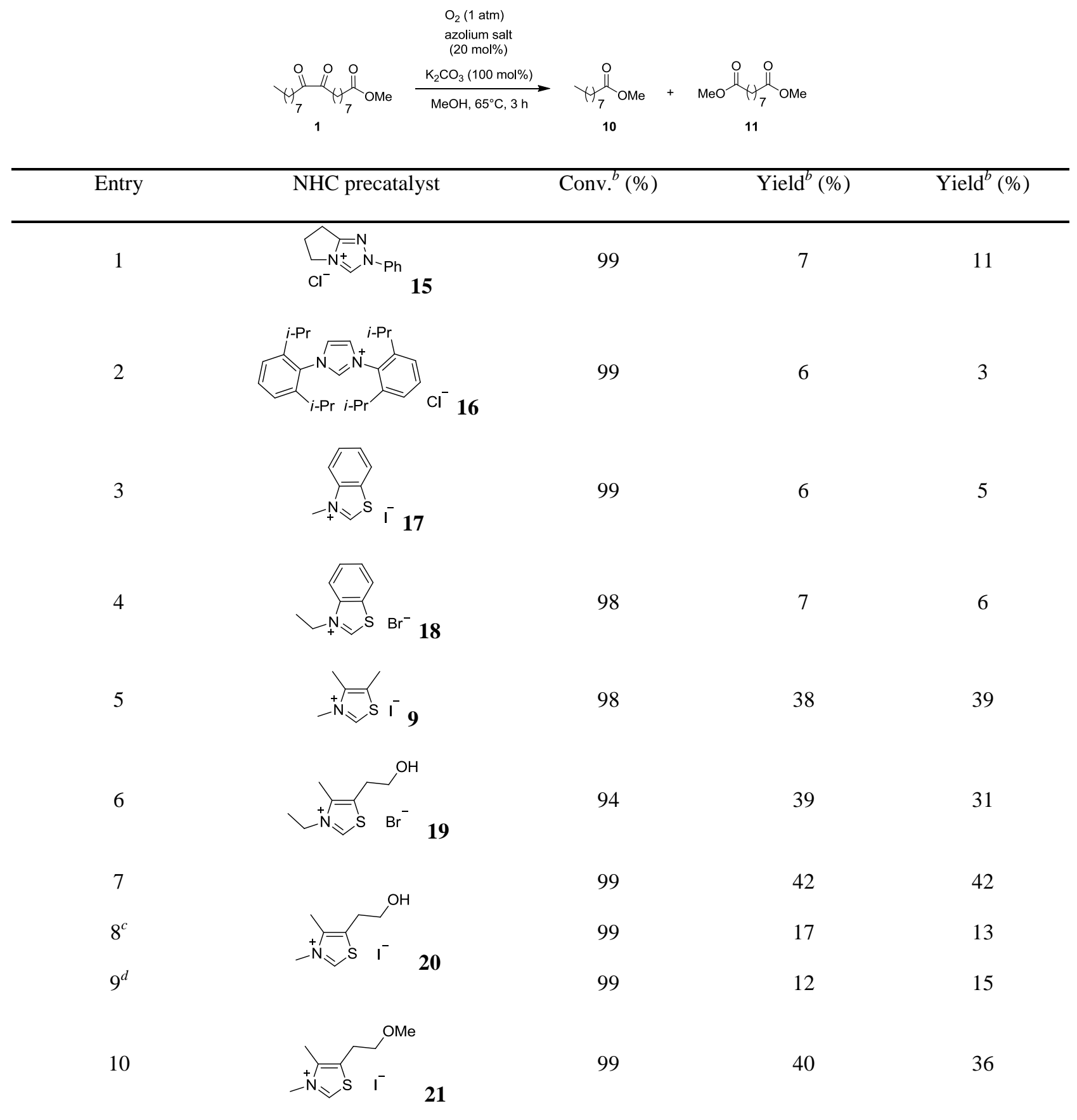

\footnotetext{
${ }^{a}$ Reaction conditions: $25-\mathrm{mL}$ Schlenk flask, diketone $1(0.5 \mathrm{mmol})$, azolium salt $(20 \mathrm{~mol} \%), \mathrm{K}_{2} \mathrm{CO}_{3}(100 \mathrm{~mol} \%)$, $\mathrm{MeOH}(0.5 \mathrm{M}), 65^{\circ} \mathrm{C}, 3 \mathrm{~h} .{ }^{b}$ Conversion and yield of products were determined by GC using $n$-hexanedecane as an internal standard. ${ }^{c} 200 \mathrm{~mol} \%$ of $\mathrm{K}_{2} \mathrm{CO}_{3}$. [d] $300 \mathrm{~mol} \%$ of $\mathrm{K}_{2} \mathrm{CO}_{3}$.
} 
Triazolium 15, imidazolium 16 and benzothiazolium salts 17-18 were first investigated and they all gave a full conversion (Table 2, entries 1-4). However, none of these catalysts could generate the desired esters with significant yields. In these cases, the heavy byproducts $\mathbf{1 2}$ and $\mathbf{1 3}$ were formed along with other unidentified heavier byproducts. The presence of aldehydes (nonanal and methyl 9-oxononanoate) was also observed by GC and their corresponding acids were also detected by mass spectroscopy (ESI, negative mode). However, the amount of the byproducts was not quantified at this stage of the study. On the contrary, only thiazolium salts $\mathbf{9}$, 19-21 could efficiently catalyze the cleavage of 1,2-diketone 1 (Table 2, entries 5-10). The best results were obtained with thiamine-based catalyst $\mathbf{2 0}$, providing a quantitative conversion and $42 \%$ yield of two esters 10 and 11 (Table 2, entry 7). Increasing the amount of $\mathrm{K}_{2} \mathrm{CO}_{3}$ or using other bases (see ESI) did not allow to improve the results (Table 2, entries 8-9). Considering that thiazolium 20 has a free hydroxy group that could be potentially oxidized during the process, thiazolium salt 21, bearing a $O$-methyl protection, was synthesized and evaluated under the same conditions (Table 2, entry 10). No better results were obtained with this catalyst, showing that oxidation of the $\mathrm{OH}$ group in thiazolium $\mathbf{2 0}$ does not occur, or if so, it has a negligible impact on the reactivity. Finally, a control experiment was also carried out using only $100 \mathrm{~mol} \%$ of $\mathrm{K}_{2} \mathrm{CO}_{3}$. Under these conditions, esters $\mathbf{1 0}$ and $\mathbf{1 1}$ can be still detected but the reaction mixture was very messy (see GC chromatogram in ESI), indicating the crucial role of the thiazolium precatalyst $\mathbf{2 0}$ to promote the desired reaction.

After optimization, the conversion was complete and the maximum yield for each ester reached a plateau at $42 \%$. To confirm this result, the reaction was scaled-up using $1 \mathrm{~g}$ of 1,2-diketone 1 derived from methyl oleate. Using thiazolium salt 20, the isolated yield of $\mathbf{1 0}$ and $\mathbf{1 1}$ reached 43 and $37 \%$, respectively, thus confirming the previous results obtained by GC titration (Scheme 3 ). 


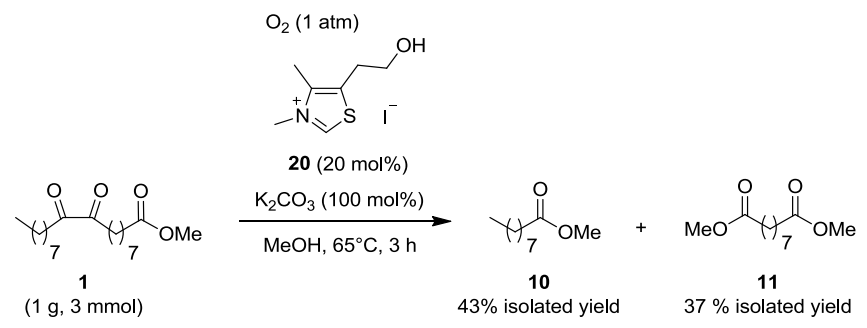

Scheme 3. Scale-up reaction for the oxidative cleavage of 1,2-diketone 1 to esters.

Based on this scale-up reaction and our previous observations, other species, representing about half of the cleavage, must be generated during the reaction. However, these species were neither detected by GC nor isolated by column chromatography. Moreover, it should be noted that an excess of the base is required to afford the highest yield of esters. So, we hypothesized that the corresponding potassium carboxylates were also formed as co-products. To evaluate this hypothesis, the cleavage reaction of 1,2-diketone $\mathbf{1}$ was carried out under optimized conditions but the work-up was modified (Scheme 4).

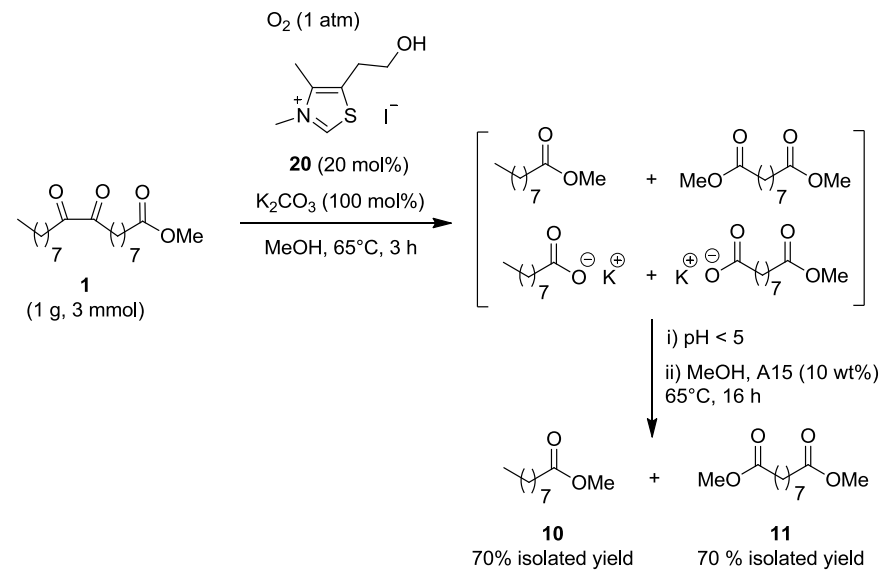

Scheme 4. Scale-up reaction for the oxidative cleavage of 1,2-diketone 1 to esters. 
An acid treatment was applied until $\mathrm{pH}<5$ to release the free acids and the formation of these species was confirmed by GC (see ESI). The esterification of the mixture in methanol in the presence of Amberlyst-15 gave esters $\mathbf{1 0}$ and $\mathbf{1 1}$ as the only products as also confirmed by GC (see ESI). Finally, the products were purified by column chromatography to give esters $\mathbf{1 0}$ and 11 with 70\% isolated yield. This result clearly indicate the formation of potassium carboxylates as reaction intermediates. Moreover, they have been detected by negative mode ESI mass spectroscopy (see ESI). The substrate scope was then investigated using a catalyst loading of 10 mol $\%^{54}$ and using an acidification/esterification work-up (Table 3). 
Table 3. Scope for the cleavage of fatty 1,2-diketones to esters. ${ }^{a}$

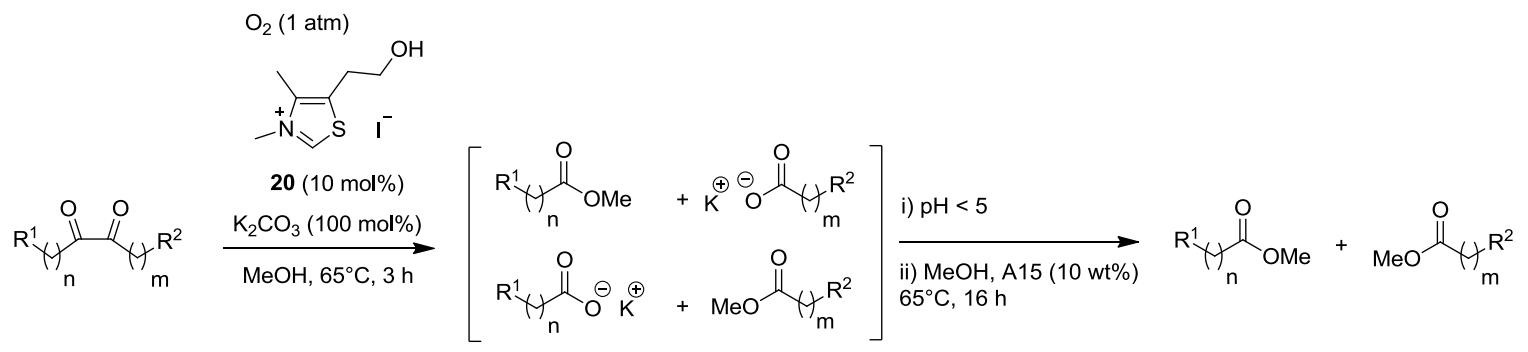

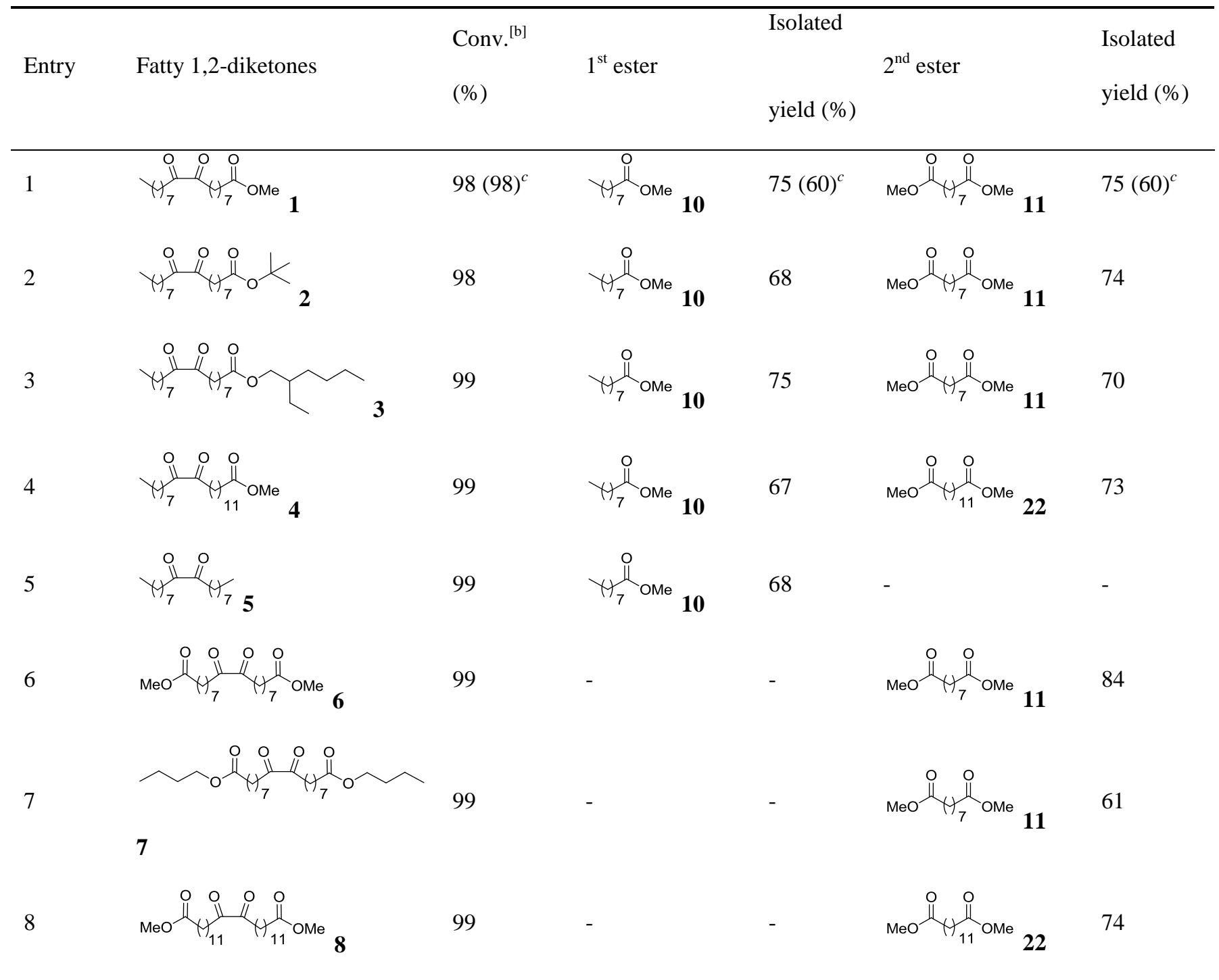

\footnotetext{
${ }^{a}$ Reaction conditions: 25 -mL Schlenk flask, diketone (0.5 mmol), thiazolium salt 20 (10 mol\%), $\mathrm{K}_{2} \mathrm{CO}_{3}(100 \mathrm{~mol} \%), \mathrm{MeOH}$ $(0.5 \mathrm{M}), 65^{\circ} \mathrm{C}, 3 \mathrm{~h} .{ }^{b}$ Conversion was determined by GC. ${ }^{c}$ Results for the scale-up reaction using $5 \mathrm{mmol}$ of diketone.
} 
Unsymmetrical fatty 1,2-diketones were first considered. Diketone 1 gave $75 \%$ of methyl pelargonate 10 and $77 \%$ of dimethyl azelate 11, thus showing that decreasing the catalyst loading to $10 \mathrm{~mol} \%$ has little impact on the results (Table 3, entry 1). However, lower yields (60\%) were obtained for a scale-up reaction using a 10-fold amount of starting material (Table 3, entry 1, results in brakets). The same esters $\mathbf{1 0}$ and $\mathbf{1 1}$ were also isolated with 68 and 74\% yield, from diketone 2 derived from tert-butyl oleate (Table 3, entry 2). This result shows that tert-butyl ester intermediates underwent transesterification in the presence of methanol and Amberlyst 15 to give the corresponding methyl esters. The same phenomenon also occurs using diketone $\mathbf{3}$ as a starting material and esters $\mathbf{1 0}$ and $\mathbf{1 1}$ were obtained with 73 and $70 \%$ yields (Table 3, entry 3).

Diketone 4, derived from methyl erucate, gave ester 10 and dimethyl brassylate 22 with 68 and 74\% yield, respectively (Table 3, entry 4). Symmetrical fatty 1,2-diketones were next considered and they all gave satisfying yields. Diketone $\mathbf{5}$ gave methyl pelargonate $\mathbf{1 0}$ as unique product with 67\% yield (Table 3, entry 5). Symmetrical diketones $\mathbf{6}$ and $\mathbf{7}$ gave dimethyl azelate $\mathbf{1 1}$ with 84 and $61 \%$ yield, respectively after (trans)esterification with methanol (Table 3, entries 6-7). Finally, diketone $\mathbf{8}$ afforded dimethyl brassylate $\mathbf{2 2}$ as the sole product with 74\% yield (Table 3, entry 8). The monoesters could find applications in the preparation of biobased surfactants while the diesters could be used as monomers for the synthesis of renewable polyesters.

\section{CONCLUSIONS}

In conclusion, we have demonstrated that fatty 1,2-diketones can be efficiently cleaved to the corresponding esters using oxygen as a clean oxidant. The reaction occurs in methanol in the presence of a thiazolium precatalyst and $\mathrm{K}_{2} \mathrm{CO}_{3}$ and generates a 1:1 mixture of methyl esters and 
potassium carboxylates. An acidic treatment of the mixture, followed by (trans)esterification with methanol, led to the desired methyl esters with good isolated yields. The optimized conditions were applied to a range of symmetrical and unsymmetrical fatty 1,2-diketones and the corresponding esters were isolated with $61-84 \%$ yield. The conditions developed in this work highlight that aliphatic (enolizable) 1,2-diketones can be cleaved with similar efficiency that aromatic 1,2-diketones (benzils).

\section{EXPERIMENTAL}

General procedure for the oxidation of fatty $\alpha$-hydroxyketones to 1,2-diketones. Following a modified reported procedure, ${ }^{51}$ in a $250-\mathrm{mL}$ two-neck flask, the $\alpha$-hydroxyketone (1 equiv) was suspended in $\mathrm{MeCN}$ and $\mathrm{VOCl}_{3}(1 \mathrm{~mol} \%)$ in $\mathrm{MeCN}$ was added dropwise over 15 minutes. The flask was equipped with an oxygen balloon and the yellow suspension was stirred at room temperature for 24 hours (the reaction was followed by GC and the completion was indicated by a green color of the reaction mixture). The reaction mixture was quenched by a saturated $\mathrm{NaHCO}_{3}$ solution (twice) and extracted with a mixture of heptane/EtOAc (1:1). The organic layer was washed with saturated $\mathrm{NH}_{4} \mathrm{Cl}$ solution (twice), saturated $\mathrm{NaCl}$ solution (twice), dried $\left(\mathrm{MgSO}_{4}\right)$, filtered and the filtrate was evaporated under reduced pressure to give the crude product. The residue was purified by column chromatography (cyclohexane/ethyl acetate 100:0 to 95:5) or by recrystallization in ethanol. 
General procedure for the organocatalytic cleavage of fatty 1,2-diketones to esters. In a 25$\mathrm{mL}$ round bottom flask, a 1,2-diketone (1 equiv), a $\mathrm{NHC}$ precatalyst (10 mol\%) and $\mathrm{K}_{2} \mathrm{CO}_{3}$ (1 equiv) were introduced under oxygen atmosphere (balloon), then $\mathrm{MeOH}$ was added. The reaction mixture was heated at $65^{\circ} \mathrm{C}$ for 3 hours. After cooling to room temperature, the mixture is filtered on sintered glass and $\mathrm{HCl}(3 \mathrm{M}$ in $\mathrm{MeOH})$ was added to reach a $\mathrm{pH}$ around 1 . Then, $10 \mathrm{wt}$ $\%$ of Amberlyst 15 (acidic resin) was added and the reaction is left overnight under stirring in $\mathrm{MeOH}$ at $65^{\circ} \mathrm{C}$. The solution is filtered through sintered glass and the solvent was evaporated under reduced pressure. The residue was purified by column chromatography (cyclohexane / ethyl acetate: 100:0 to $96: 4)$.

\section{ASSOCIATED CONTENT}

Supporting Information. The supporting information contains the general procedures, the characterization data of fatty 1,2-diketones and esters, as well as ${ }^{1} \mathrm{H}$ and ${ }^{13} \mathrm{C}$ NMR spectra of all compounds.

\section{AUTHOR INFORMATION}

\section{Corresponding Author}

* E-mail: nicolas.duguet@univ-lyon1.fr

ORCID

Nicolas Duguet: 0000-0002-9425-7450

Marc Lemaire: 0000-0003-2800-0590 


\section{Author Contributions}

The manuscript was written through contributions of all authors. All authors have given approval to the final version of the manuscript.

\section{ACKNOWLEDGMENT}

The authors thank the SAS PIVERT for a Ph.D. grant to N. D. Vu and a master grant to R. Chavallard (GENESYS program - project WP3P21-Bioaldehydes). This work was performed in partnership with the SAS PIVERT, within the frame of the French Institute for the Energy Transition (Institut pour la Transition Energétique (ITE) P. I. V. E. R. T. (http://www.institutpivert.com)) selected as an Investment for the Future (“Investissements d'Avenir"). This work was supported, as part of the Investments for the Future, by the French Government under the reference ANR-001-01. The region Auvergne-Rhône-Alpes is also acknowledged for a Ph.D. grant to T. De Dios Miguel (Pack Ambition La Région Auvergne-Rhône-Alpes Recherche - project VALCOUPENZ). This project has been labeled by AXELERA (www.axelera.org), pôle de compétitivité Chimie-environnement in Auvergne-Rhône-Alpes.

\section{REFERENCES}

1 Corma, A.; Iborra, S.; Velty, A. Chemical routes for the transformation of biomass into chemicals. Chem. Rev. 2007, 107, 2411-2502.

2 Biermann, U.; Friedt, W.; Lang, S.; Lühs, W.; Machmüller, G.; Metzger, J. O.; Rüsch gen. Klaas, M.; Schäfer, H. J.; Schneider, M. P. Oils and Fats as Renewable Raw Materials in Chemistry. Angew. Chem., Int. Ed. 2000, 39, 2206-2224. 
3 Biermann, U.; Bornscheuer, U.; Meier, M. A. R.; Metzger, J. O.; Schäfer, H. J. Oils and Fats as Renewable Raw Materials in Chemistry. Angew. Chem., Int. Ed. 2011, 50, 3854-3871.

4 Meier, M. A. R.; Metzger, J. O.; Schubert, U. S. Plant Oil Renewable Resources as Green Alternatives in Polymer Science. Chem. Soc. Rev. 2007, 36, 1788-1802.

5 Xia, Y.; Larock, R. C. Vegetable Oil-Based Polymeric Materials: Synthesis, Properties, and Applications. Green Chem. 2010, 12 (11), 1893-1909.

6 Fraile, J. M.; García, J. I.; Herrerías, C. I.; Pires, E. Synthetic Transformations for the Valorization of Fatty Acid Derivatives. Synthesis. 2017, 49 (07), 1444-1460.

7 Foley, P.; Kermanshahi pour, A.; Beach, E. S.; Zimmerman, J. B. Derivation and synthesis of renewable surfactants. Chem. Soc. Rev. 2012, 41, 1499-1518.

8 Hill, K. in Surfactants from Renewable Resources; ed. Kjellin, M., Johansson, I., Eds.; John Wiley \& Sons, Ltd., 2010.

9 Capderou, M.; Pale, P. Valorisation of agricultural resources: synthesis of green tensioactives agents from carbohydrates. C. R. Chim. 2004, 7, 607-610.

10 Lichtenthaler, F. W.; Peters, S. Carbohydrates as green raw materials for the chemical industry. $C$. $R$. Chim. 2004, 7, 65-90.

11 Jose, J.; Pourfallah, G.; Merkley, D.; Li, S.; Bouzidi, L.; Lopes Leao; A.; Narine, S. S. Thermoplastic polyesters and Co-polyesters derived from vegetable oil: synthesis and optimization of melt polycondensation for medium and long chain poly( $\omega$-hydroxyfatty acid)s and their ester derivatives. Polym. Chem. 2014, 5, 3203-3213.

12 Jose, J.; Pourfallah, G.; Lopes Leao, A.; Narine, S. S. Influence of monomeric and polymeric structure on the physical properties of thermoplastic polyesters derived from hydroxy fatty acids. Polym. Int. 2014, 63, $1902-1911$.

13 Diamond, M. J.; Binder, R. G.; Applewhite, T. H. Alkaline cleavage of hydroxy unsaturated fatty acids. I. Ricinoleic acid and lesquerolic acid. J. Am. Oil Chem. Soc. 1965, 42, 882-884.

14 Naughton, F. C. Production, chemistry, and commercial applications of various chemicals from castor oil. J. Am. Oil Chem. Soc. 1974, 51, 65-71. 
15 Spiccia, N. D.; Border, E.; Illesinghe, J.; Jackson, W. R.; Robinson, A. J. Preparation of a Nylon-11 Precursor from Renewable Canola Oil. Synthesis 2013, 45, 1683-1688.

16 Forman, G. S.; Bellabarba, R. M.; Tooze, R. P.; Slawin, A. M. Z.; Karch, R.; Winde, R. Metathesis of renewable unsaturated fatty acid esters catalysed by a phoban-indenylidene ruthenium catalyst. $J$. Organomet. Chem. 2006, 691, 5513-5516.

17 Burdett, K. A.; Harris, L. D.; Margl, P.; Maughon, B. R.; Mokhtar-Zadeh, T.; Saucier, P. C.; Wasserman, E. P. Renewable Monomer Feedstocks via Olefin Metathesis: Fundamental Mechanistic Studies of Methyl Oleate Ethenolysis with the First-Generation Grubbs Catalyst. Organometallics 2004, 23, 2027 2047.

18 Thomas, R. M.; Keitz, B. K.; Champagne, T. M.; Grubbs, R. H. Highly Selective Ruthenium Metathesis Catalysts for Ethenolysis. J. Am. Chem. Soc. 2011, 133, 7490-7496

19 Mol, J. C. Application of olefin metathesis in oleochemistry: an example of green chemistry. Green Chem. 2002, 4, 5-13.

20 Enferadi Kerenkan, A.; Béland, F.; Do, T.-O. Chemically catalyzed oxidative cleavage of unsaturated fatty acids and their derivatives into valuable products for industrial applications: a review and perspective. Catal. Sci. Technol. 2016, 6, 971-987.

21 Köckritz, A.; Martin, A. Synthesis of azelaic acid from vegetable oil-based feedstocks. Eur. J. Lipid Sci. Technol. 2011, 113, 83-91

22 Spannring, P.; Bruijnincx, P. C. A.; Weckhuysen, B. M.; Klein Gebbink, R. J. M. Transition metalcatalyzed oxidative double bond cleavage of simple and bio-derived alkenes and unsaturated fatty acids. Catal. Sci. Technol. 2014, 4, 2182-2209.

23 Wang, M.; Ma, J.; Liu, H.; Luo, N.; Zhao, Z.; Wang, F. Sustainable Productions of Organic Acids and Their Derivatives from Biomass via Selective Oxidative Cleavage of C-C Bond. ACS Catal. 2018, 8 , $2129-2165$.

24 Louis, K.; Vivier, L.; Clacens, J.-M.; Brandhorst, M.; Dubois, J.-L.; De Oliveira Vigier, K.; Pouilloux, Y. Sustainable route to methyl-9-hydroxononanoate (polymer precursor) by oxidative cleavage of fatty acid methyl ester from rapeseed oil. Green Chem. 2014, 16, 96-101. 
Omonov, T. S.; Kharraz, E.; Foley, P.; Curtis, J. M. The production of biobased nonanal by ozonolysis of fatty acids. $R S C A d v . \mathbf{2 0 1 4}, 4,53617-53627$.

Lundin, M. D.; Danby, A. M.; Akien, G. R.; Binder, T. P.; Busch, D. H.; Subramaniam, B. Liquid CO 2 as a Safe and Benign Solvent for the Ozonolysis of Fatty Acid Methyl Esters. ACS Sustainable Chem. Eng. 2015, 3, 3307-3314.

27 Holde, D.; Marcusson, J. Oxydation von Oelsaure durch Permanganat bei Gegenwart geringer Mengen Alkali. Ber. 1903, 36, 2657-2662.

28 King, G. a-Ketol Carboxylic Acids. Part I. 9-Hydroxy-10-keto- and 10-Hydroxy-9-keto-stearic Acids. J. Chem. Soc. 1936, 1788-1792

29 Morrell, R. S.; Phillips, E. O. Oxidation of the drying oils and cognate substances. IV. Properties of the ketol grouping. J. Soc. Chem. Ind., London, 1938, 57, 245-247

30 Hilditch, T. P.; Plimmer, H. The Oxidation of Hydroxyketostearic Acids in Presence of Alcoholic Alkali. J. Chem. Soc. 1942, 204-206

31 Coleman, E.; Ricciuti C.; Swern, D. Improved Preparation of 9(10),10(9)-Ketohydroxystearic Acids by Oxidation of Oleic Acid with Potassium Permanganate in Neutral Solution. J. Am. Chem. Soc., 1956, 78, $5342-5345$

32 Cramp, W. A.; Julietti, F. J.; McGhie, J. F.; Rao, B. L.; Ross, W. A. Aliphatic Acids. Part I. Some Aliphatic Ketol-acids and Related Compounds. J. Chem. Soc. 1960, 4257-4263.

33 Brousse, E.; Lefort, D. Oxydation d'époxystéarate de méthyle en acyloïne par le diméthylsulfoxyde. $C$. $R$. Acad. Sci. 1965, 261(groupe 8), 1990-1991.

34 Fermeier, S.; Metzger, J. O. Synthesis of New Heterocyclic Fatty Compounds. Eur. J. Org. Chem. 2003, 2003, 885-893.

35 Jensen, H. P.; Sharpless, K. B. Improved procedure for the direct oxidation of olefins to .alpha.-diketones by potassium permanganate in acetic anhydride. J. Org. Chem. 1974, 39, 2314-2314.

36 Doll, K. M.; Bantchev, G. B.; Murray, R. E. Bismuth(III) Trifluoromethanesulfonate Catalyzed RingOpening Reaction of Mono Epoxy Oleochemicals To Form Keto and Diketo Derivatives. ACS Sustainable Chem. Eng. 2013, 1, 39-45 
37 Khurana, J. M.; Kandpal, B. M. A novel method of synthesis of 1,2-diketones from 1,2-diols using Nbromosuccinimide. Tetrahedron. Lett. 2003, 44, 4909-4912.

38 Vu, N. D.; Guicheret, B.; Duguet, N.; Metay, E.; Lemaire, M. Homogeneous and Heterogeneous Catalytic (Dehydrogenative) Oxidation of Oleochemical 1,2-Diols to $\alpha$-Hydroxyketones. Green Chem. 2017, 19, 3390-3399.

39 Guicheret, B.; Bertholo, Y.; Blach, P.; Raoul, Y.; Métay, E.; Lemaire, M. A Two-Step Oxidative Cleavage of 1,2-Diol Fatty Esters into Acids or Nitriles by a Dehydrogenation-Oxidative Cleavage Sequence. ChemSusChem 2018, 11, 3431- 3437.

40 Deruer, E.; Duguet, N.; Lemaire, M. Thiazolylidene-catalyzed cleavage of methyl oleate-derived $\alpha$ hydroxy ketone to the corresponding free aldehydes. ChemSusChem 2015, 8, 2481-2486.

41 Vu, N. D.; Bah, S.; Deruer, E.; Duguet, N.; Lemaire, M. Robust organocatalysts for the cleavage of vegetable oil derivatives to aldehydes through retro-benzoin condensation. Chem. - Eur. J. 2018, 24, $8141-8150$.

42 Charvieux, A.; Vu, N. D.; Duguet, N.; Lemaire, M. Valorization of methyl azelaaldehydate - a vegetable oil-based platform molecule - to monomers through Stetter reaction. Eur. J. Org. Chem. 2019, 12511256.

43 Khurana, J. M.; Sharma, P.; Gogia, A. Oxidative cleavage of 1,2-diols, $\alpha$-ketols and 1,2-diketones with aqueous sodium hypochlorite. Org.Prep. Proced. Itl 2007, 39, 185-189.

44 Yan, J.; Travis, B. R.; Borhan, B. Direct Oxidative Cleavage of $\alpha$ - and $\beta$-Dicarbonyls and $\alpha$ Hydroxyketones to Diesters with $\mathrm{KHSO}_{5}$. J. Org. Chem. 2004, 69, 9299-9302.

45 Kwart, H.; Baevsky, M. The Cyanide Ion Catalyzed Cleavage of Aromatic $\alpha$-Diketones. J. Am. Chem. Soc. 1958, 80, 580-588.

46 Cho, D.-G.; Kim, J. H.; Sessler, J. L. The Benzil-Cyanide Reaction and Its Application to the Development of a Selective Cyanide Anion Indicator. J. Am. Chem. Soc. 2008, 130, 12163-12167.

47 Delany, E. G.; Fagan, C.-L.; Gundala, S.; Zeitler, K.; Connon, S. J. Aerobic oxidation of NHC-catalysed aldehyde esterifications with alcohols: benzoin, not the Breslow intermediate, undergoes oxidation. Chem. Commun. 2013, 49, 6513-6515. 
48 Gundala, S.; Fagan, C.-L.; Delany, E. G.; Connor, S. J. Organocatalytic Aerobic Oxidative Cleavage of Cyclic 1,2-Diketones. Synlett 2013, 24, 1225-1228.

49 Shimakawa, Y.; Morikawa, T.; Sakaguchi, S. Facile route to benzils from aldehydes via NHC-catalyzed benzoin condensation under metal-free conditions. Tetrahedron Lett. 2010, 51, 1786-1789.

50 Wilson, J.; Chen, E. Y.-X. Organocatalytic Cross-Coupling of Biofuranics to Multifunctional Difuranic C11 Building Blocks. ACS Sustainable Chem. Eng. 2016, 4, 4927-4936.

51 Kirihara, M.; Ochiai, Y.; Takizawa, S.; Takahata, H.; Nemoto, H. Aerobic oxidation of $\alpha-$ hydroxycarbonyls catalysed by trichlorooxyvanadium: efficient synthesis of $\alpha$-dicarbonyl compounds. Chem. Commun. 1999, 1387-1388.

52 A temperature of $65^{\circ} \mathrm{C}$ was found optimal for this reaction. Lower temperatures gave lower yields of esters, even with extended reaction time. See supporting information for details.

53 Bortolini, O.; Fantin, G.; Fogagnolo, M.; Giovannini, P. P.; Venturi, V.; Pacifico, S.; Massi, A. $\alpha-$ Diketones as acyl anion equivalents: a non-enzymatic thiamine-promoted route to aldehyde-ketone coupling in PEG400 as recyclable medium. Tetrahedron 2011, 67, 8110-8115.

54 See supporting information for the optimization of the catalyst loading. 
Table of Contents:

“Organocatalytic scissors" were used to cleave fatty 1,2-diketones to esters using oxygen as a clean oxidant.

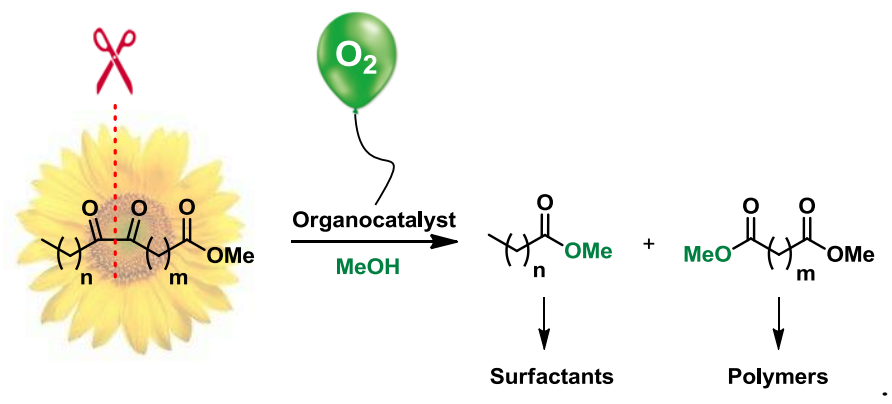

